\title{
Analysis of the e-commerce development of Leshan silicon industry Clusters
}

\author{
Hongwei Hui ${ }^{1}$ Ying Zhang ${ }^{2}$ \\ 1. Management Department, The Engineeing Technical College of Chengdu University of Technology, \\ Sichuan Leshan , China ,614007. \\ 2. Management Department, The Engineeing Technical College of Chengdu University of Technology, \\ Sichuan Leshan , China ,614007.
}

\begin{abstract}
Promoting the development of Leshan silicon industry through e-commerce is an effective way to solve the current problems of the development of the industry. Silicon industry developed rapidly in China in recent years, But in the process of development it has problems such as lack of core technical support, the lack of high-end products, pollution,it has not formed effective integration within the industry, lack of competitive advantage,etc. To address and solve these problems to make Leshan silicon industry to adapt to market needs, It can achieve real prosperity of silicon industry.
\end{abstract}

Keywords: Leshan silicon clusters, e-commerce platform, system design and application

\section{Introduction}

End of 2010, The quantity of China's major producers of polysilicon is approximately 55 , The production has reached about 14 million tons, Accounting for about $39 \%$ of the world.

Leshan silicon industry formed of the 1964's Mindanao semi Factory, Now there are 22 silicon backbone enterprises in Leshan, The quality of associated enterprises is 32, There are a number of strong silicon materials and solar photovoltaic companies in Leshan such as East Automobile Group Emei Semiconductor Material Factory, Yongxiang company and Ledian Tianwei, Xinguang Silicon Industry,
Leshan - Phoenix Semiconductor Co., Ltd, Leshan Jia Yang New Energy Co., Ltd. etc. It begun to take shape the development of circular economy industrial park in Leshan City High-tech Zone, Emeishan, Leshan Wutongqiao etc. Can be seen from the production, Leshan polysilicon production began to achieve a zero breakthrough from 1965, It is the location of the first one kiloton polysilicon plant, Up to now formed an annual output of 7,500 tons of polysilicon production capacity, Nearly 70 percent of the polysilicon production of the country in Leshan.

\section{Problems on the Domestic silicon industry}

\section{1 .Not mastered the core technology}

Currently the core technology of polysilicon production still rests in the hands of the developed country. Because our country donot master the $f$ the technology and crafts yet, There are still risks of China's polysilicon production in energy consumption, cost, pollution control and other aspects. When the international market price of polysilicon from the highest $\$ 450 / \mathrm{kg}$, "Diving" to today's \$25/ kg, European companies can still survive, China's polysilicon enterprises have been unbearable price fluctuations, The whole industry suffered a huge blow, Just our country put into a number of projects, they were on struggling to survive.

2.2 . There is a big gap between the quality of products

China can produce purity of 119 Polycrystalline 
high-end products is rare, $80 \%$ of the polysilicon manufacturers are not master the core technology, Not on the scale of a small factory, These manufacturers of both backward and excess production capacity,It is a major worry of the development of China's photovoltaic industry, China has been the production of solar grade polysilicon products mostly 2,3-class products, It cannot scale supply the need of the technical requirements of the semiconductor integrated circuit products with polysilicon.

\section{3 .Pollution}

At present China's polysilicon production is mainly the use of "modified Siemens process", This approach is necessary to produce one ton of polysilicon produced 15 tons of highly toxic silicon tetrachloride. Theoretically each ton of polysilicon produced 12 tons of silicon tetrachloride, The reality is often greater than 20 tons, Domestic enterprises disposal silicon tetrachloride treatment technology is being low processing power, handling high energy consumption, processing costs are high, It bring about more than $80 \%$ of the toxic silicon tetrachloride can not be effectively addressed, Therefore, Domestic polysilicon enterprises are facing serious constraints is how to deal with domestic polysilicon silicon tetrachloride.

\section{The problems of Leshan silicon industry}

Leshan silicon industry cluster is a development imbalance, It is mainly in the silicon material production enterprise, and lack of other relevant enterprises, Especially the processing power is not enough about hazardous and noxious liquid silicon tetrachloride of polysilicon corrosive byproducts, This will result in Leshan polysilicon production costs are high, Pollution, unbalanced development.

Because of incomplete market information, Asymmetry, leading to high transaction costs market, The production is behind the market demand, Especially the polysilicon manufacturing industries are Cyclical industry, Amplitude huge international market price of polysilicon, It makes polysilicon production enterprises are facing a huge industry cyclical risks, How to solve the problem of asymmetric information market, And reduce market transaction costs, It must be solved of Leshan silicon and photovoltaic industry.

Situation of the enterprise and product promotion is not enough. Although Leshan has many polysilicon business. But they have not high Visibility and little influence, Facing fierce competition from domestic and foreign counterparts, Leshan silicon clusters must be solved of how to expand the influence and reduce cost of sales and shaping the corporate brand.

Consolidation within the industry is not sufficient. Although Leshan silicon clusters are more companies, But their collaboration and communication is not close enough, It Can not lead to the complementary advantages and integration of resources between enterprises, So it can not effectively improve the overall competitiveness and competitive advantage of industrial clusters.

\section{Necessity to develop the e-commerce of silicon industrial clusters}

It is Established a vertical e-commerce platform about Silicon materials and photovoltaic products industry, Leshan should take use of resources and technological advantages, They also should integrate domestic polysilicon industry chain of Upper, middle and downstream resources, Leshan take advantage of "National Development and byproducts silicon material utilization industrial base", In the present case is imperative to build their world silicon industry brands.

Through the e-commerce platform, They can open up the silicon industry cluster of linkages among upper ,middle and downstream, It can Promote industrial integration and optimization; The use of e-commerce platform can advertise Leshan industrial policy and assist the government to attract foreign investment work, 
It can encourage more polysilicon and downstream enterprises and relevant research institutions to locat in Leshan.It can reduce imbalances of Leshan polysilicon production enterprises, It can guide Silicon ore suppliers at home and abroad to sales Silicon Mine on Silicon Network e-commerce platform, The collection of Leshan silicon material manufacturing enterprise take participation in procurement, It greatly reduce the cost of procurement of raw materials; They can use the e-commerce platform to publicize and promote the Leshan silicon materials and photovoltaic industry cluster at home and abroad, Through cluster cooperation and website Promotion to increase sales opportunities and expand revenue; The introduction of intelligence experts by e-commerce platform operators to collection, collation, analysis intelligence information about Polysilicon and photovoltaic industry at home and abroad advanced technology. Crafts, price dynamics, and other relevant policies. It is in order to provide information to support enterprises in the cluster,Integration silicon materials and photovoltaic industries upper, middle and downstream related enterprises by use of e-commerce platform to achieve the sharing industrial supply chain information, complementarity and integration of information resources; Application of the world silicon network e-commerce platform to improve enterprise management level and efficiency and thereby reducing management costs through enterprise Clusters; It is promote supply chain face to face communication and collaboration by using line forum being held of platform.

Currently, there are no similar sites abroad, Domestic and similar sites are mainly two, They are China Silicon Network and silicon Network, China Silicon Network's attribution is Jiangsu Lianyungang,It is does not record in the internet Network Information Center, It does not provide information on purchase and sales services, There are a large number of link error,
It also did not indicate a clear site owner, It does not pose any competition of the project built by the e-commerce platform, So below is no longer analysis it.

Silicon Network's website vested in Shanghai Silicon Network Technology Co., Ltd., It was established in January 29, 2004, Its main services of silicon products and raw materials manufacturers shch as industrial silicon (silicon metal), multi / monocrystalline silicon, silica fume, silicon carbide, ferrosilicon, manganese, silicon, barium, calcium, silicon magnesium etc. The site provides domestic enterprises purchasing these products, sales and intelligence information,It also support line activities, It have an influence in the industry. But from website design standards and function of silicon Network, It's design is not high and it's function relatively simple; Its main targets are all domestic users, It hasn't influence in foreign; It is very limited for the product. It did not form a collection of industry chain upper, middle and lower reaches of enterprise information; Meanwhile, the Silicon Network does not provide management services within the enterprise.

For the above, Leshan silicon clusters in the development of e-commerce can be focused on semiconductor silicon(Polysilicon, Monocrystalline) and PV industry on the whole industry chain, middle and downstream enterprises and products; For domestic and foreign user groups; It provide information service including international market; It provide the software services of enterprise management based on Web; Providing expert technical and management consulting, Thereby it formed a favorable competitive situation commerce.

\section{The design and application of silicon clusters commerce platform system}

Taking into account the years of application development which based on B / S mode three-tier system architecture and mature technology,It has case of a mature to refer, It has short development cycle and low development 
costs, Therefore it is decided to adopt the model developed the E-commerce platform silicon clusters. The e-commerce platform which can be divided into three basic levels, They are user interface layer,business logic layer and data access layer.The corresponding structure as shown below:

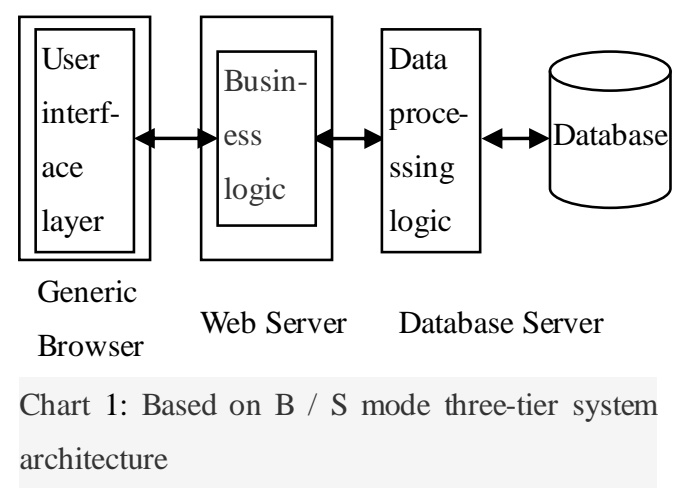

Software embedded in the e-commerce platform for enterprise management can use the three-tier architecture, It can also use the Web-based C / S structure. This architecture is likely to B / S architecture, On the server side they are using the Web server and in the lower based on the HTML or HTTPS protocol, The main difference is no longer using common browser, But for different applications, it develop different dedicated client browser. Its system architecture is shown in Chart 2:

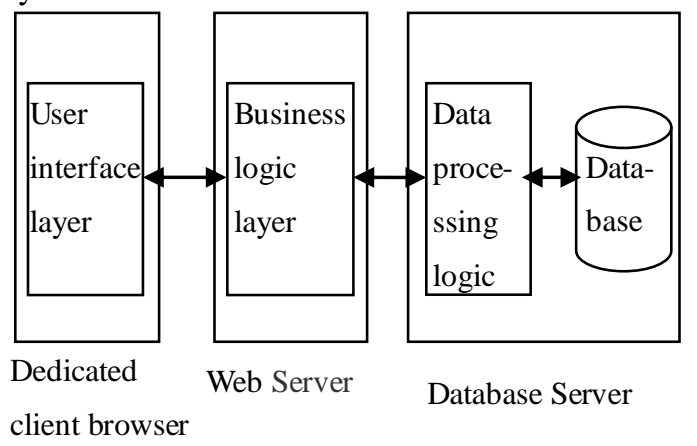

Chart 2: c/s architecture based on web

It a more flexible user interface becase of dedicated client browser,Therefore it can be more suitable for some complex applications. Current this technology of client / server design architecture which based on web has matured and gained wide application, Such as
RSS news reader, and some read books online software, There are application for some requirements of a strong security such as China Merchants Bank online banking professional version, etc.

The security of E-commerce platform in the transaction is closely related to the security of the Internet. The problem are mainly related to the secure transmission of information and security certification of Online payment in the transaction process. Specifically, They should include data confidentiality, data Integrity, Identification and non-repudiation of business activities. Considering the above factors, The e-commerce platform guarantees platform security by using PKI technology.

The main function the about designing of Platform : purchasing, sales, products, publishing and management of advertising information; intelligence information and management of prices, policies, technologies and crafts; Search and subscription information; Management platform of member; Management of enterprise online shops; Management of ERP online platform inside the enterprise; Platform of traffic statistics and analysis; Function of RSS Channe; BBS ; Functions of online communication ;etc.

The designing for search engine optimization SEO about E-commerce platform should take into account the needs of search engine optimization platform before the design of the system. After in the construction of e-commerce platform and the test is passed, It should focuses on the construction of the information content about the platform itself, The primary task is training professional maintenance personnel for the content of e-commerce platform.

Personnel of content maintenance need to continue to collect the information about related industries, markets, technologies, policies of crystalline silicon of abroad and home, Then they organize and publish; Platform operators 
need to encourage and guide Leshan silicon industry cluster enterprises,related scientific research institutes and research institute.to initiative to posted corporate procurement, production, sales, management and other related information by using of E-commerce platform; Platform operators need to optimize internal process design, Through SaaS services.It achieve tracking management about information flow within the enterprise, All daily business activities of Leshan silicon materials and photovoltaic products industry chain transferred to the e-commerce platform, It cab be fullly realize the E-commerce operations of Leshan silicon materials and photovoltaic products and the management of paperless enterprise. Through the above three aspects, It's target is strived to make crystalline silicon related industries enterprises from purchasing, sales in the e-commerce platform to working in e-commerce platform.

They should increase the platform for the promotion on riching sound E-commerce platform content. They can consider the well-known website(Such as Alibaba international and domestic stations)and search engine(Such as Google, Baidu, Yahoo, MSN, etc) to promote, After several months of a row to promote, The platform on the network in crystalline silicon-related industries to become the most famous platform, And through the promotion of continuous, It cab be maintained a global network of silicon ranking and the network's brand and influence. The purpose is to let people in the industry first think of the e-commerce platform when they think of crystalline silicon-related industries, They will first think of Leshan when they think of crystalline silicon-related industries. It can be to establish a unified image and unified regional brand about Leshan silicon clusters by Using of the e-commerce platform, Leshan silicon clusters make bigger stronger brand.

\section{References}

[1] Guang jun-fang, Chen yang, "Lei shaomin,Analysis on silicon Industry development",Light metal , pp. 01-04, 2012.

[2] Jiang xiao, Jiang ronghua, Zhou hongwei, "Competitiion of global polysilicon industry", New materials industry, pp. 28-36, 2012.

[3] Michael Blaha,"Modeling and Design of Object-Oriented on UML", People Post Press, 2010 